\title{
Current limiting and negative differential resistance in indium oxide based ceramics
}

\author{
A.B. Glot ${ }^{1}$, S.V. Mazurik ${ }^{2}$, B.J. Jones ${ }^{3,{ }^{*}}$, A.N. Bondarchuk ${ }^{1}$, \\ R. Bulpett ${ }^{3}, \mathrm{~N}$. Verma $^{3}$ \\ ${ }^{1}$ División de Estudios de Posgrado, Universidad Tecnológica de la Mixteca, Huajuapan de León, Oaxaca \\ 69000 México \\ ${ }^{2}$ Dep. of Radioelectronics, Dniepropetrovsk National University, Dniepropetrovsk 49050 Ukraine \\ ${ }^{3}$ Experimental Techniques Centre, Brunel University, Uxbridge, Middlesex, UB8 3PH, UK \\ *Corresponding author Tel: +44 (0)1895 265409 / 255793 Fax: +44 (0)1895 812544 email: b.j.jones@ physics.org
}

\begin{abstract}
.
Indium oxide based ceramics with bismuth oxide addition were sintered in air in the temperature range 800-1300 ${ }^{\circ} \mathrm{C}$. Current-voltage characteristics of $\mathrm{In}_{2} \mathrm{O}_{3}-\mathrm{Bi}_{2} \mathrm{O}_{3}$ ceramics sintered at different temperatures are weakly nonlinear. After an additional heat treatment in air at about $200{ }^{\circ} \mathrm{C}$ samples sintered at a temperature within the narrow range of about $1050-1100^{\circ} \mathrm{C}$ exhibit a current-limiting effect accompanied by low-frequency current oscillations. It is shown that the observed electrical properties are controlled by the grain-boundary barriers and the heat treatment in air at $200{ }^{\circ} \mathrm{C}$ leads to the decrease in the barrier height. Electrical measurements, scanning electron microscopy and $\mathrm{X}$-ray photoelectron spectroscopy results suggest that the current-limiting effect observed in $\mathrm{In}_{2} \mathrm{O}_{3}-\mathrm{Bi}_{2} \mathrm{O}_{3}$ may be explained in terms of a modified barrier model; the observed current-limiting effect is the result of an increase of barrier height with increasing electric field, due to additional oxygen absorption. It is found that $\mathrm{In}_{2} \mathrm{O}_{3}-\mathrm{Bi}_{2} \mathrm{O}_{3}-\mathrm{Co}_{3} \mathrm{O}_{4}$ $\mathrm{Cr}_{2} \mathrm{O}_{3}$ ceramic exhibits current-voltage characteristics with negative differential resistance due to Joule micro heating.
\end{abstract}

Keywords: A. Sintering; B. Grain Boundaries; C. Electrical Properties; Indium Oxide; E. Varistors.

\section{Introduction}

At low electric fields the current-voltage characteristic of a sample is generally linear and Ohm's law is obeyed. An increase in the electric field can cause some deviations from Ohm's law. Two cases are possible: superlinear, exploited in varistors, where the current rises more strongly than voltage, or sublinear where current rises more weakly than voltage. The nonlinear current-voltage characteristic can be approximated by the empirical equation

$$
I=B U^{\beta}
$$

where $I$ is the current, $U$ is the voltage, $\beta$ is the nonlinearity coefficient $\beta=(U / I)(d I / d U)$ and $B$ is some constant. In the case of superlinear current-voltage characteristic $\beta>1$ and in the case of sublinear current-voltage characteristic $\beta<1$.

At the present time, sublinear current-voltage characteristics have been found in some polycrystalline materials [1-7] and several explanations of this effect were suggested [1,3,8-11]. In particular, such behaviour has been observed in $\mathrm{In}_{2} \mathrm{O}_{3}$-SrO ceramics [5,6]. In this material the addition of strontium leads to an increase in resistivity at low electric fields and the appearance of non-Ohmic behaviour (saturation and even decrease in current density) at higher fields. The mechanism of this current limiting effect in $\mathrm{In}_{2} \mathrm{O}_{3}-\mathrm{SrO}$ ceramics can be related to the increase in the grain-boundary barrier height with applied electric field due to the additional oxygen adsorption [12].

However, in $\mathrm{In}_{2} \mathrm{O}_{3}$-SrO ceramics quite strong degradation is observed and, as a result, the current limiting effect disappears after some time. From a materials science view-point it would be interesting to study indium oxide based non-Ohmic ceramics with other additives, with the aim to produce a more 
reproducible and stable current limiting effect. Indium oxide exhibits n-type conduction and is widely used for the preparation of transparent electrodes for optoelectronic devices [13-15] and gas-sensors [1618]. However, it is well known that the addition of bismuth oxide $\left(\mathrm{Bi}_{2} \mathrm{O}_{3}\right)$ improves the sintering and promotes an increase in the nonlinearity coefficient in zinc oxide based and tin dioxide based varistor ceramics [19-24]. This suggests that bismuth oxide addition may also induce non-ohmic behavior in indium oxide ceramics. Moreover, some bismuth oxide phases in such ceramics can have ionic conduction with oxygen ion as a carrier [25-27] this can be favourable for the manifestation of the current limiting mechanism proposed by Bondarchuk et al. [12].

To investigate this idea, we present a study of the electrical properties and microstructure of indium oxide based $\mathrm{In}_{2} \mathrm{O}_{3}-\mathrm{Bi}_{2} \mathrm{O}_{3}$ ceramics sintered at different temperatures and with different post-production heattreatment processes.

\section{Experimental Method}

Indium oxide based ceramics (mol.\%) $95 \mathrm{In}_{2} \mathrm{O}_{3}-5 \mathrm{Bi}_{2} \mathrm{O}_{3}$ were prepared by the conventional mixed oxides method $[5,24]$ with sintering at temperature in the wide range of 800-1300 ${ }^{\circ} \mathrm{C}$. Ceramics (mol.\%) 98.5 $\mathrm{In}_{2} \mathrm{O}_{3}-0.5 \mathrm{Bi}_{2} \mathrm{O}_{3}-0.5 \mathrm{Co}_{3} \mathrm{O}_{4}-0.5 \mathrm{Cr}_{2} \mathrm{O}_{3}$ were sintered at $1200{ }^{\circ} \mathrm{C}$.

A Zeiss Supra 35VP field emission scanning electron microscope (FE-SEM) was used to obtain secondary electron, backscattered electron (BSE) and in-lens images of sample surfaces, fracture surfaces and polished cross-sections. Elemental composition information from BSE data were augmented with energy dispersive X-ray microanalysis (EDX) obtained with Oxford Instruments INCA system attached to the SEM. Accelerating voltages of $5 \mathrm{keV}$ were utilized to enable elemental analysis whilst ensuring low penetration depth. X-ray photoelectron spectroscopy (XPS) was performed with a VG EscaLab210 (Al anode), the composition of the surface was calculated from high resolution expansions utilising empirically derived atomic sensitivity factors [28]. X-ray diffraction was conducted with a Bruker D8 AXS spectrometer.

The density, $\rho$, of sintered samples was determined using hydrostatic weighting method in distilled water. The theoretical density $\rho_{T}=7.294 \mathrm{~g} \cdot \mathrm{cm}^{-3}$ of the studied material was calculated taking into account the chemical composition before sintering. It was assumed that physical and chemical processes during sintering have negligible effect on the chemical composition. The closed porosity was estimated from the expression $p_{C}=1-\rho \cdot \rho_{T}^{-1}$.

Ag-electrodes fired in air at $800{ }^{\circ} \mathrm{C}$ were used [24]. An additional heat treatment was conducted in air at $800{ }^{\circ} \mathrm{C}$ for 1 hour with slow heating and slow cooling. An additional heat treatment in air atmosphere at $200{ }^{\circ} \mathrm{C}$ was performed by slowly heating a sample with Ag-electrodes up to $200{ }^{\circ} \mathrm{C}$, maintaining this temperature for 1 hour and subsequently quenching to room temperature.

Current-voltage characteristics were studied, utilizing a Keithley-237 unit. At automatic recording voltage was applied during $10 \mathrm{~ms}$ (current was measured at the end of this interval) and the voltage was reduced to zero for a period of $100 \mathrm{~ms}$. Electric field $E_{-5}$ was calculated at the current

density $j=1 \cdot 10^{-5} \mathrm{~A} \mathrm{~cm}^{-2}$.

Current-voltage characteristics of the samples with negative differential resistance were studied in the "current source" regime. In this case rectangular current pulses with successively increasing and decreasing amplitude (current increment $1 \cdot 10^{-5} \mathrm{~A}$ ) were used. Two examination modes were employed. In mode $\mathrm{A}$, sample overheating was avoided by using a short pulse duration $10 \mathrm{~ms}$ with a pause between pulses $1 s$. In mode B, sample overheating was achieved using pulse duration $4 s$ with a pause between pulses $4 s$. 
Small-signal capacitance versus dc voltage was measured using a QuadTech 7600 LCR meter and a Keithley 6487 voltage source, both controlled by computer. Rectangular voltage pulses with increasing amplitude (voltage increment $5 \mathrm{~V}$, pulse duration $4 s$, pause between pulses $4 s$ ) were used.

Capacitance was measured at frequency $100 \mathrm{~Hz}$ with ac voltage amplitude $0.5 \mathrm{~V}$. The run "down" gives the same data.

Temperature dependence of dc electrical conductivity $\sigma(T)$ was obtained in the range of 290-370 K in air by heating and cooling of a sample with a rate of about $1.5 \mathrm{~K} / \mathrm{min}$. The activation energy of electrical conduction $E_{\sigma}$ was found from the equation:

$$
\sigma(T)=\sigma_{0} \exp \left(-E_{\sigma} / k T\right)
$$

where $\sigma$ is the electrical conductivity, $\sigma_{0}$ is a constant, $k$ is the Boltzmann's constant, $T$ is the absolute temperature.

\section{Experimental Results and Discussion}

3.1 Sintering Temperature. SEM micrographs of samples obtained at different sintering temperature are shown in figure 1. The grain size increases with sintering temperature; for example, in the sample sintered at $1100{ }^{\circ} \mathrm{C}$ (figure $1 \mathrm{~b}$ ) grains in the range $0.5-2 \mu \mathrm{m}$ are observed, in contrast to the sample sintered at $800^{\circ} \mathrm{C}$ (figure $1 \mathrm{a}$ ) where the grain size is $200-500 \mathrm{~nm}$. Analysis of both as-sintered surfaces (figures 1 $\mathrm{a}, \mathrm{c}$ ) and fracture cross sections (for example, figure $1 \mathrm{~b}$ ) shows grains in sample bulk are similar in size and morphology to those at the sinter surface. Analysis of lower magnification SEM images (such as figure $1 \mathrm{~d}$ ) shows the porous nature of the samples. The density of sintered samples are $\rho=4.972 \mathrm{~g} \cdot \mathrm{cm}^{-3} \quad$ (sintering temperature $800^{\circ} \mathrm{C}$ ), $\rho=5.206 \mathrm{~g} \cdot \mathrm{cm}^{-3} \quad\left(1100^{\circ} \mathrm{C}\right)$ and $\rho=5.896 \mathrm{~g} \cdot \mathrm{cm}^{-3}\left(1300^{\circ} \mathrm{C}\right)$. The closed porosity was estimated from these results as $31.8 \%\left(800^{\circ} \mathrm{C}\right)$, $28.6 \%\left(1100^{\circ} \mathrm{C}\right)$ and $19.2 \%\left(1300^{\circ} \mathrm{C}\right)$.

SEM backscattered electron analysis of a polished section of the sample sintered at $1100^{\circ} \mathrm{C}$, in conjunction with the topography information from the in-lens image of the same area, shows a distinct, atomically heavier phase at a proportion of the grain boundaries. Analysis of elemental composition by EDX shows indium oxide grains with predominantly bismuth oxide at the grain boundaries. XRD measurements are consistent with bismuth oxide as a boundary phase, rather than incorporated into $\operatorname{In}_{2} \mathrm{O}_{3}$ lattice. This is consistent with $\mathrm{Bi}_{2} \mathrm{O}_{3}$ addition responsible for liquid-phase sintering.

Current-voltage characteristics of $\mathrm{In}_{2} \mathrm{O}_{3}-\mathrm{Bi}_{2} \mathrm{O}_{3}$ ceramics sintered at different temperatures (fig.2) are weakly superlinear $(\beta>1)$. The increase in sintering temperature causes a decrease in the low-field conductivity (at $800-1050^{\circ} \mathrm{C}$ ) followed by an increase at $1050-1300^{\circ} \mathrm{C}$. This means that electric field, $E_{-5}$, at fixed current density ( $j=1 \cdot 10^{-5} \mathrm{~A} \mathrm{~cm}^{-2}$ ) passes through a maximum (fig.3, curve 1).

If conduction is controlled by the grain-boundary barriers, then the barrier height in this case should also pass through a maximum. If we additionally assume that the Fermi level in the bulk of indium oxide grains is situated not more than several tenths of $\mathrm{eV}$ below the conduction band edge and, therefore, the barrier height $\varphi$ in the studied $\operatorname{In}_{2} \mathrm{O}_{3}-\mathrm{Bi}_{2} \mathrm{O}_{3}$ ceramics is only slightly less than the activation energy $E_{\sigma}$ of electrical conduction, $\varphi \cong E_{\sigma}$, then one can expect that the activation energy also should pass through the maximum. Experimental data confirm such assumption: the activation energy for different sintering temperatures indeed goes through a maximum at $1100^{\circ} \mathrm{C}$ (Fig.3, curve 2).

Probably, due to n-type conduction in indium oxide, the increase in sintering temperature up to $1100^{\circ} \mathrm{C}$ leads to some growth in oxygen content at the grain boundaries related to the presence of liquid $\mathrm{Bi}_{2} \mathrm{O}_{3}$ though at higher temperatures the evaporation of bismuth oxide becomes significant and oxygen content at the grain boundaries is decreased. In any case, the observed correlation supports the assumed barrier 
conduction mechanism: the higher the barrier height, the lower the conductivity (Fig.2) and, therefore, the higher the electric field at fixed current density (Fig.3, curve 1).

3.2 Additional Heat Treatments. In the samples sintered at different temperatures, sublinear $\mathrm{I}(\mathrm{U})$ and current oscillations were not initially manifested. It has been shown previously [29] that in $\operatorname{In}_{2} \mathrm{O}_{3}-\mathrm{Bi}_{2} \mathrm{O}_{3}$ ceramics obtained at $1100{ }^{\circ} \mathrm{C}$, current limiting and low-frequency current oscillations effects appeared after a heat treatment in air at about $200{ }^{\circ} \mathrm{C}$ with sharp cooling. Therefore, samples sintered at different temperatures were subjected to the additional heat treatment at $200{ }^{\circ} \mathrm{C}$. It was observed that samples sintered at 1050 and $1100^{\circ} \mathrm{C}$ exhibit sublinear current-voltage characteristics, relatively weak in the sample sintered at $1050^{\circ} \mathrm{C}$ and quite strong for the sample sintered at $1100^{\circ} \mathrm{C}$ (Fig.4). Samples sintered at other temperatures retain the slight superlinearity of current-voltage characteristic, even after the additional heat treatment. Low-frequency current oscillations accompany the observed sublinearity but to avoid some complexity, current-voltage characteristics in the sublinear region are presented using average current values. The current limiting effect and low-frequency current oscillations are reproducible.

The reproducibility in current-voltage characteristics of the sample sintered at $1100 \mathrm{C}$ and additionally heat treated at $200 \mathrm{C}$ to generate the current limiting effect is illustrated in Fig.5. Voltage increase (Fig.5, curve 1) and decrease (Fig.5, curve 2) give nearly the same $\mathrm{I}(\mathrm{U})$ characteristics. This current-voltage characteristic is symmetric (Fig. 5, curves 1 and 3). At voltages higher than about $50 \mathrm{~V}$ the scattering of experimental points is observed. It is due to the current oscillations. $\operatorname{In} \operatorname{In}_{2} \mathrm{O}_{3}-\mathrm{Bi}_{2} \mathrm{O}_{3}$ ceramics the current limiting effect is always accompanied by low-frequency current oscillations and both phenomena are quite reproducible. The degradation of the current-voltage characteristics after numerous measurements in $\mathrm{In}_{2} \mathrm{O}_{3}-\mathrm{Bi}_{2} \mathrm{O}_{3}$ ceramics is significantly less than was found in $\mathrm{In}_{2} \mathrm{O}_{3}-\mathrm{SrO}$ ceramics [12]. Therefore, $\mathrm{In}_{2} \mathrm{O}_{3}-\mathrm{Bi}_{2} \mathrm{O}_{3}$ ceramics have substantial advantages in comparison to $\mathrm{In}_{2} \mathrm{O}_{3}-\mathrm{SrO}$ ceramics as a material where the current limiting effect is observed.

So far we relate both the current limiting effect and current oscillation to the grain-boundary barriers, which appear in these ceramics as a result of sintering in the oxidizing atmosphere. The additional heat treatment at $200{ }^{\circ} \mathrm{C}$ affects electrical properties of the samples sintered at $1100^{\circ} \mathrm{C}$; it would therefore be interesting to study the effect of this heat treatment on the barrier height. As shown in figure 6, the heat treatment in air at $200^{\circ} \mathrm{C}$ with rapid quenching causes the barrier height to decrease for all sintering temperatures. An additional heat treatment in air at $800{ }^{\circ} \mathrm{C}$ causes barrier height to increase, equally or exceeding initial values. The barrier height as a function of sintering temperature has a maximum at about $1050-1100^{\circ} \mathrm{C}$ regardless of the subsequent heat-treatment process.

The system with decreased barrier height after the heat treatment in air at $200^{\circ} \mathrm{C}$ appears to be quite stable. Similar time-stability of electrical properties was observed in $\mathrm{SnO}_{2}-\mathrm{ZnO}-\mathrm{Bi}_{2} \mathrm{O}_{3}$ varistor ceramics after the heat treatment in air at $200-400{ }^{\circ} \mathrm{C}$ [21]. Only an increase in applied electric field causes additional oxygen absorption resulting in an increase of barrier height as electric field increases, thus causing the observed current-limiting effect.

The observed decrease in the barrier height after the heat treatment in air at $200^{\circ} \mathrm{C}$ could be explained by a decrease in oxygen content at the grain boundaries. Therefore, to further explore the oxygen content in the sample we studied XPS spectra of the samples sintered at $1100{ }^{\circ} \mathrm{C}$, with and without additional heat treatment in air at $200^{\circ} \mathrm{C}$. There is a slight increase in the relative oxygen content of the sample surface following heat-treatment; however, this can most likely be related to the decrease in hydrocarbon contamination on the sample surface, as there is no significant change in the ratio of oxygen content to the sum of the indium and bismuth contents. More noticeably, the XPS data show a change in the indium:bismuth ratio at the sample surface; this ratio increases by a factor of approximately 1.4 following heat treatment at $200^{\circ} \mathrm{C}$. There is no concurrent shift in the photoelectron peak position, indicating at most only a negligible change in the oxidation state. This alteration in the surface chemistry is not accompanied by a change in the morphology, or by a change in the bulk In:Bi ratio as detected by EDX - a technique with a penetration depth in the order of micrometres, rather than the $1-10 \mathrm{~nm}$ analysis depth of XPS. However, the EDX spectra do suggest some change in the oxygen content within the grains, suggesting the heat treatment and rapid quench do cause some redistribution of the oxygen within the ceramic. Although the difference in oxygen content is not entirely clear, we believe that the change in chemistry of the grain boundaries with additional heat treatment processes results in the observed current-limiting 
effect, the result of an increase in barrier height with applied electric field, caused by additional oxygen absorption [12].

The current limiting effect observed in the $\mathrm{In}_{2} \mathrm{O}_{3}-\mathrm{Bi}_{2} \mathrm{O}_{3}$ ceramics studied here is markedly different from the electrical properties of $\mathrm{ZnO}-\mathrm{Bi}_{2} \mathrm{O}_{3}$-based $[20,22]$ or $\mathrm{SnO}_{2}-\mathrm{Bi}_{2} \mathrm{O}_{3}$-based ceramics $[21,23,24]$, which exhibit the varistor effect. In both groups of materials the grain-boundary barriers play the main role in the conduction process. The varistor effect in $\mathrm{ZnO}$-based and $\mathrm{SnO}_{2}$-based materials is related to the lowering of the barrier height with increase in electric field [30-34]. But perhaps the feature of barriers to be decreased (in varistor ceramics) or increased (in ceramics with current limiting behaviour) with the application of voltage depends on the specific impurities at the grain boundaries. Thus, an alteration of the grain-boundary impurities could change the electrical properties of such ceramics.

To examine this, $\mathrm{In}_{2} \mathrm{O}_{3}-\mathrm{Bi}_{2} \mathrm{O}_{3}-\mathrm{Co}_{3} \mathrm{O}_{4}-\mathrm{Cr}_{2} \mathrm{O}_{3}$ ceramics were sintered. Cobalt and chromium oxides additives were chosen to reproduce the favorable conditions for obtaining of varistor ceramics in a system $\mathrm{ZnO}-\mathrm{Bi}_{2} \mathrm{O}_{3}-\mathrm{Sb}_{2} \mathrm{O}_{3}-\mathrm{Co}_{3} \mathrm{O}_{4}-\mathrm{MnO}-\mathrm{Cr}_{2} \mathrm{O}_{3}$ with a high nonlinearity coefficient $\beta \cong 50$ [20]. Current-voltage characteristics of the obtained sample are shown in Fig.7. In contrast to $\operatorname{In}_{2} \mathrm{O}_{3}-\mathrm{Bi}_{2} \mathrm{O}_{3}$ samples, currentvoltage characteristics are superlinear and can be varistor-type (Fig.7, curves 1-2) or can be superlinear and contain a region with negative differential resistance $R_{d}=d U / d I<0$ (in the case if measurements are performed permitting overheating of a sample) (Fig.7, curves 3-4). Earlier currentvoltage characteristics with switching or negative differential resistance were observed in various nonoxide and oxide systems (see, for example [34,35]).

In spite of the strong difference between two types of superlinear curves each current-voltage characteristic is quite reproducible for increase and decrease of voltage (Fig.7, curves 1-2 and curves 3-4). Though, in the case of negative differential resistance (Fig.7, curves 3-4) some hysteresis is found due to thermic mechanism of the negative differential resistance effect. The sensitivity of current-voltage characteristic to the variation of voltage pulse duration, a wide current region with negative differential resistance and the absence of a region with positive differential resistance at higher current (Fig.7) confirm the thermic nature of observed negative differential resistance effect.

For additional confirmation of the thermic nature of this negative differential resistance effect, lowfrequency capacitance versus dc voltage was obtained (Fig.7, curve 5). In the case of negative differential resistance related to Joule heating the low-frequency capacitance should becomes negative (inductive behaviour of ac current) [36]. Indeed, negative capacitance is detected, even at low voltages when overheating only begins.

\section{Conclusions}

$\mathrm{In}_{2} \mathrm{O}_{3}-\mathrm{Bi}_{2} \mathrm{O}_{3}$ ceramics with current-limiting effect (sublinear $\mathrm{I}(\mathrm{U})$ dependence, nonlinearity coefficient < 1) are investigated. The materials were sintered in air in the temperature range $800-1300{ }^{\circ} \mathrm{C}$. The grain size increases with increase in sintering temperature. It is found that sublinear $\mathrm{I}(\mathrm{U})$ characteristics are observed only in $\operatorname{In}_{2} \mathrm{O}_{3}-\mathrm{Bi}_{2} \mathrm{O}_{3}$ ceramics sintered at a temperature within the narrow range of about 1050$1100{ }^{\circ} \mathrm{C}$, and with subsequent heat treatment in air at $200{ }^{\circ} \mathrm{C}$ with rapid quenching. It is shown that the observed electrical properties are controlled by the grain-boundary barriers and the heat treatment leads to the decrease in the barrier height. Electrical measurements, scanning electron microscopy and X-ray photoelectron spectroscopy results suggest that the current-limiting effect observed in $\operatorname{In}_{2} \mathrm{O}_{3}-\mathrm{Bi}_{2} \mathrm{O}_{3}$ can be explained in terms of the modified barrier model proposed earlier for the explanation of similar effect in $\mathrm{In}_{2} \mathrm{O}_{3}$-SrO ceramics. It is found that $\mathrm{In}_{2} \mathrm{O}_{3}-\mathrm{Bi}_{2} \mathrm{O}_{3}-\mathrm{Co}_{3} \mathrm{O}_{4}-\mathrm{Cr}_{2} \mathrm{O}_{3}$ ceramic material exhibits current-voltage characteristics with negative differential resistance due to Joule micro heating. 


\section{Acknowledgements}

This study was performed in part in the frames of the project SEP-2003-C02-42821, CONACYT, México. Funding from the Royal Society, United Kingdom (2007R1/R26999) is gratefully acknowledged. We thank L Anguilano for technical assistance.

\section{References}

[1] Kutty, T. R. N., and Ravi, V., Current-limiting property of n-BaTiO 3 ceramics. Mater. Sci. Eng. B 25 (1994) 119-131.

[2] Chen, J., Chen, J.Y., Lee., J.Y.M., An investigation on the leaking current and time dependent dielectric breakdown of ferroelectric lead-zirconate-titanate thin film capacitors for memory device applications. Appl. Phys. Lett., 69 (1996) 4011-4013.

[3] Pompe, T., Srikant, V., and Clarke, D.R., Acoustoelectric current saturation in c-axis fiber-textured polycrystalline zinc oxide films. Appl. Phys. Lett. 69 (1996) 4065-4067.

[4] Neto, J. A. D., Pulcinelli, S. H., and Santilli, C. V., In Proceedings of the International Conference on Electronic Ceramics and Applications, p409 (1996).

[5] Glot, A., Behr, G., and Werner, J., Current Limiting Effect in $\operatorname{In}_{2} \mathrm{O}_{3}$ Ceramics Based Structures. Key Engineering Materials. 206-213 (2002) 1441-4.

[6] Glot, A., Bondarchuk, A., Mazurik, S., Behr, G., and Werner, J., Positive Temperature Coefficient of Resistance in Indium Oxide Ceramics. Key Engineering Materials, 206-213 (2002) 1437-40

[7] Leite, E. R., Lee, E. J., Ribeiro, C., and Longo, E., Controlled thickness deposition of ultrathin ceramic films. J. Am. Ceram. Soc. 89 (2006) 2016-2020

[8] Goldman, E. I., and Zhdan, A. G., Electrical conduction in semiconductors with intergranular barriers. Sov. Phys. Semicond. 10 (1976) 1839-1845

[9] Pike, G. E., and Seager, C. H., The dc voltage dependence of semiconductor grain-boundary resistance. J. Appl. Phys. 50 (1979) 3414-3422.

[10] Stolichnov I., and Tagantsev, A., Space-charge influenced-injection model for conduction in $\mathrm{Pb}\left(\mathrm{Zr}_{\mathrm{x}} \mathrm{Ti}_{1-\mathrm{x}}\right) \mathrm{O}_{3}$ thin films. J. Appl. Phys. 84 (1998) 3216-3225.

[11] Glot, A.B., and Bondarchuk, A.N., Sublinear current-voltage behavior of oxide ceramics. Inorg. Mater. 35 (1999) 532-534.

[12] Bondarchuk, A., Glot, A., Behr, G. and Werner, J., Current saturation in indium oxide based ceramics. Eur. Phys.J: Appl. Phys. 39 (2007) 211-217.

[13] Kuo, Y., Characterization of indium tin oxide and reactive ion etched indium tin oxide surfaces. Jpn. J. Appl. Phys., 29 (1990) 2243-6.

[14] Wen, S.J., Couturier, G., Chaminade, J.P., Marquestaut, E., Claverie, J., and Hagenmuller, P., Electrical Properties of Pure $\mathrm{In}_{2} \mathrm{O}_{3}$ and Sn-Doped $\mathrm{In}_{2} \mathrm{O}_{3}$ Single-Crystals and Ceramics. J. Sol. St. Chem. 101 (1992) 203-210.

[15] Behr, G., Werner, J., Oswald, S., Krabbes, G., Dordor, P., Elefant, D., and Pitschke, W., $\mathrm{In}_{2} \mathrm{O}_{3}$ : differences in the chemical and physical behaviour of single crystal, ceramics and fine powders. Solid State Ionics, 101-103 (1997) 1183-7.

[16] Trofimenko, N.E., Baran, S.V., Masherova, N.P., Lesnikovich, K.A., Production and use of new materials - properties of ceramics and sensors based on modified indium oxide. Russian J. Appl. Chem., 68 (1995) 397-399.

[17] Yamaura, H., Jinkawa, J., Tmamaki, J., Moriya, K., Miura, N., and Yamazoe, N., Indium oxidebased gas sensor for selective detection of CO. Sens. Actuators B 35-36 (1996) 325-332.

[18] Manno, D., Micocci, G., Serra, A., Di Giulio, M. and Tepore, A., Structural and electrical properties of $\mathrm{In}_{2} \mathrm{O}_{3}-\mathrm{SeO}_{2}$ mixed oxide thin films for gas sensing applications. J. Appl. Phys. 88 (2000) 6571-7

[19] Glot A.B., Hogarth C.A., Bulpett R, and Reynolds A.J., Characterization of the ZnO-SnO2-CoOBi2O3 ceramic material sintered at high-temperature, Journal of Materials Science Letters 4 (1985) 963-966

[20] Matsuoka, M., Non-Ohmic Properties of Zinc Oxide Ceramics. Jpn. J. Appl. Phys. 10 (1971) 736746

[21] Glot, A.B., Chakk, A.M., Chernyi, B.K., and Yakunin, A.Y., Dependence of the electrical conductivities of the semiconductors $\mathrm{ZnO}-\mathrm{SnO}_{2}-\mathrm{Bi}_{2} \mathrm{O}_{3}$ on the temperature and additional heattreatment procedure. Inorg. Mater. 10 (1974) 1866-1868

[22] Avdeenko, B.K., Glot, A.B., Ivon, A.I., Chernenko, I.M., and Schelokov A.I., Thermostimulated conduction of zinc oxide ceramics of different composition. Inorg. Mater. 16 (1980) 1059-1060 
[23] Glot, A.B., and Zlobin, A.P., Non-Ohmic conductivity of tin dioxide ceramics. Inorg. Mater. 25 (1989) 274-276

[24] Skuratovsky, I., Glot, A., Di Bartolomeo, E., Traversa, E. and Polini, R., The effect of humidity on the voltage-current characteristic of $\mathrm{SnO}_{2}$ based ceramic varistor. J. Eur. Ceram. Soc. 24 (2004) 2597-2604.

[25] Harwig, H.A., and Gerards, A.G., Electrical properties of the $\alpha, \beta, \gamma$ and $\delta$ phases of bismuth sesquioxide. J. Solid State Chem. 26 (1978) 265-274

[26] Verkerk, M. J. and Burggraaf, A. J., High Oxygen Ion Conduction in Sintered Oxides of the Bi2O3Dy2O3 System, J. Electrochem. Soc. 128 (1981) 75-82.

[27] Punn, R., Feteira, A.M., Sinclair, D.C. and Greaves, C., Enhanced Oxide Ion Conductivity in Stabilized - $\mathrm{Bi}_{2} \mathrm{O}_{3}$, J. Am. Chem. Soc. 128 (2006) $15386-15387$

[28] Wagner, C. D., Davis, L. E., Zeller, M. V., Taylor, J. A., Raymond, R. H. and Gale, L. H., Empirical atomic sensitivity factors for quantitative analysis by electron spectroscopy for chemical analysis. Surf. Interface Anal. 3 (1981) 211-225

[29] Glot, A., Mazurik, S., Bondarchuk, A., Low frequency current oscillations in $\operatorname{In}_{2} \mathrm{O}_{3}-\mathrm{Bi}_{2} \mathrm{O}_{3}$ non-Ohmic ceramics. Electroceramics VIII. 8th Intl. conf. on electronic ceramics and their applications, 25-28 August, 2002, Rome, Italy. VA-016-P, p.158. (2002)

[30] Mahan, G.D., Levinson, L.M. and. Philipp, H.R, Theory of conduction in ZnO varistors J. Appl. Phys., 1979, 50[4], 2799-2812.

[31]Pike, G.E., Electronic properties of $\mathrm{ZnO}$ varistors: a new model. In Grain Boundaries in Semiconductors. Proc. Mater. Res. Soc. Ann. Meet., ed. G.E. Pike, C.H.Seager, and H.J.Leamy. Elsevier, 1982, pp.369-379.

[32] Vanadamme, L.K.J. and Brugman, J.C. Conduction mechanisms in ZnO varistors. J Appl Phys. 51 (1980) 4240-4244

[33] Glot, A.B. A simple approach to oxide varistor materials. J. Mater. Sci. 41 (2006) 5709-5711.

[34] Glot. A.B. Non-ohmic Conduction in Oxide Ceramics: Tin Dioxide and Zinc Oxide Varistors. In: Ceramic Materials Research Trends, Ed. P.B.Lin, Nova Science Publishers, Inc., 2007, p. 227-273.

[35]El-Hofy, M.. Grain Boundary defects Induced Switching in Zn- Bi- Mo Ceramic. Defect and Diffusion Forum 251-252 (2006) pp. 13-20. Trans Tech Publications, Switzerland.

[36]Ivanov, G.A., Abagyan, S.A., and Minaev, V.S.. Negative capacitance of a device with Scharacteristic. Soviet. Phys. Semicond. 6[4] (1972) 720-722. 

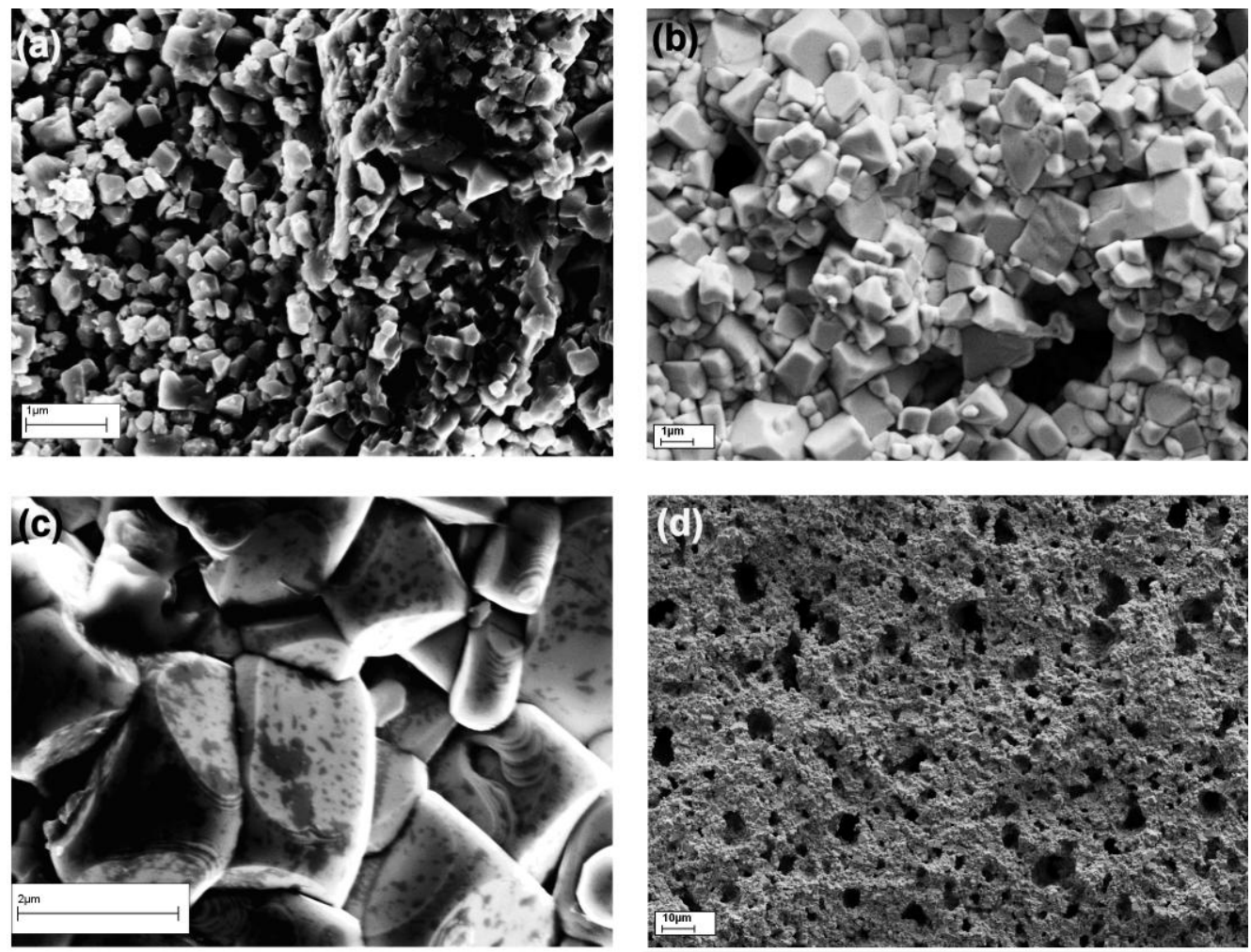

Fig.1. SEM micrographs of $\operatorname{In}_{2} \mathrm{O}_{3}-\mathrm{Bi}_{2} \mathrm{O}_{3}$ ceramics sintered at (a) $800^{\circ} \mathrm{C}$, (b) $1100^{\circ} \mathrm{C}$ and (c) $1300^{\circ} \mathrm{C}$. SEM images of as-sintered surfaces $(a, c)$ and fracture surfaces $(b, d)$ show grain size distribution and porosity.

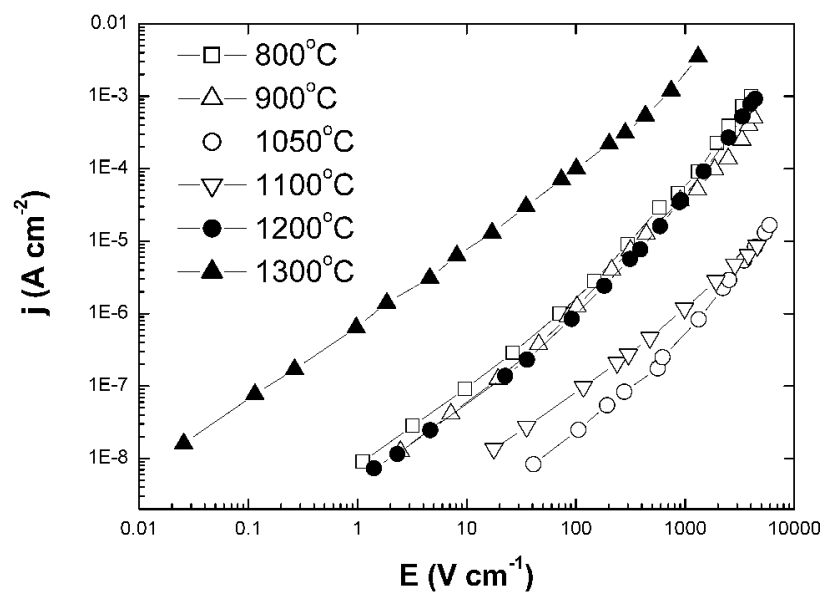

Fig.2. Current-voltage characteristics of $\operatorname{In}_{2} \mathrm{O}_{3}-\mathrm{Bi}_{2} \mathrm{O}_{3}$ ceramics sintered at different temperatures. 


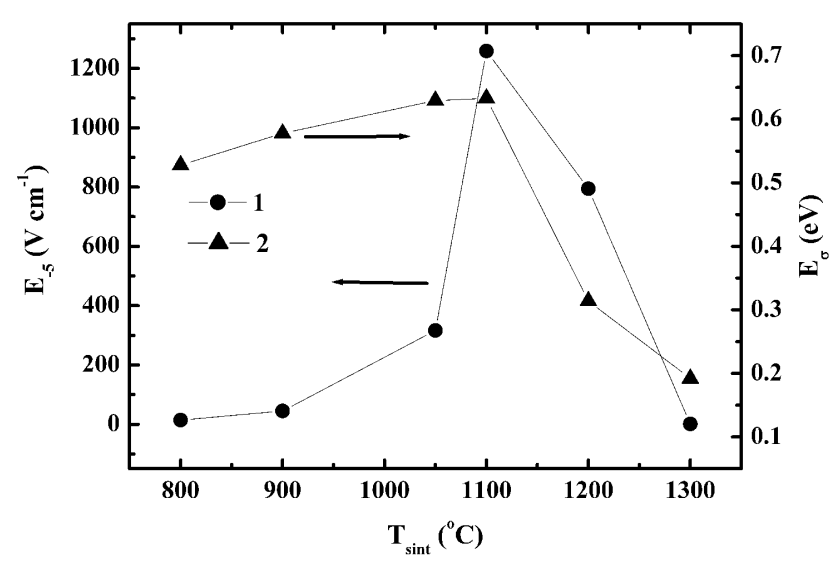

Fig.3. (1) electric field at fixed current density and (2) activation energy of conduction versus sintering temperature

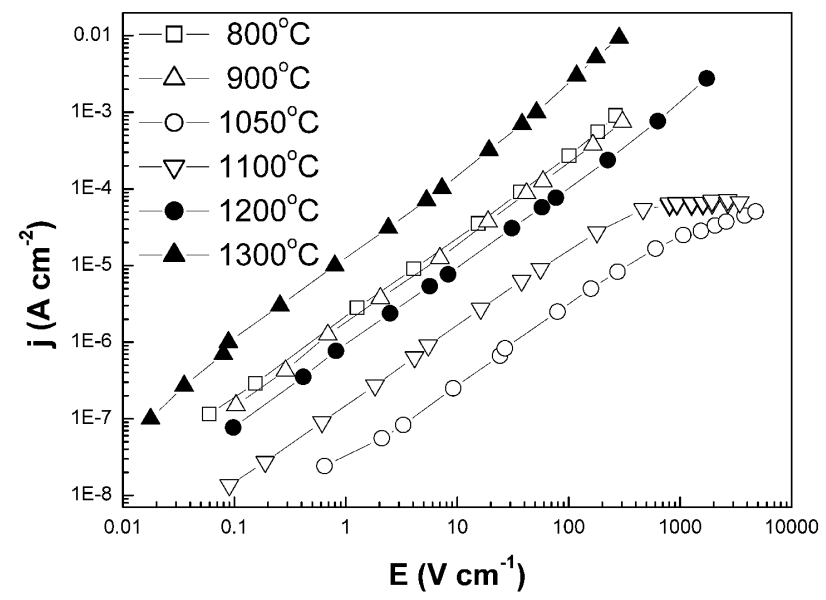

Fig.4. Effect of the heat treatment in air at $200^{\circ} \mathrm{C}$ on current-voltage characteristics of $\operatorname{In}_{2} \mathrm{O}_{3}-\mathrm{Bi}_{2} \mathrm{O}_{3}$ ceramics sintered at different temperatures

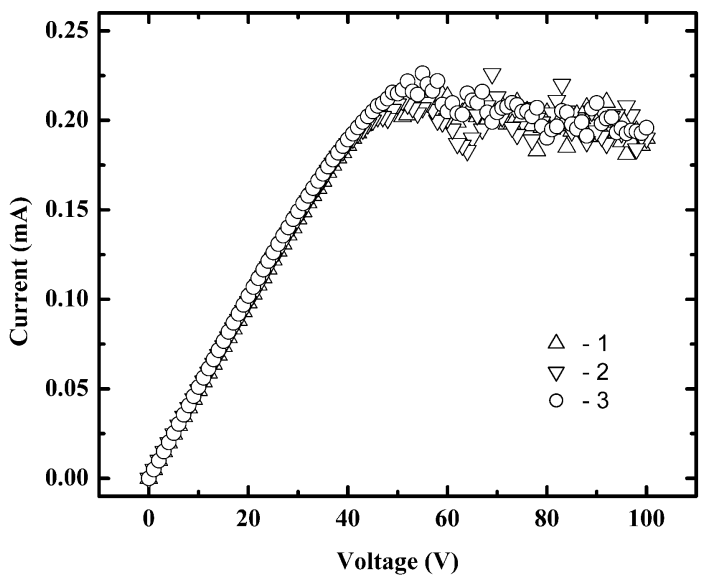

Fig.5. Current-voltage characteristics of the sample $\mathrm{In}_{2} \mathrm{O}_{3}-\mathrm{Bi}_{2} \mathrm{O}_{3}$ sintered at $1100 \mathrm{C}$ and additionally heat treated at $200 \mathrm{C}$. I(U) characteristics are obtained at increase (1) and decrease (2) of voltage and at opposite polarity (3). Current limiting is accompanied by current oscillations 


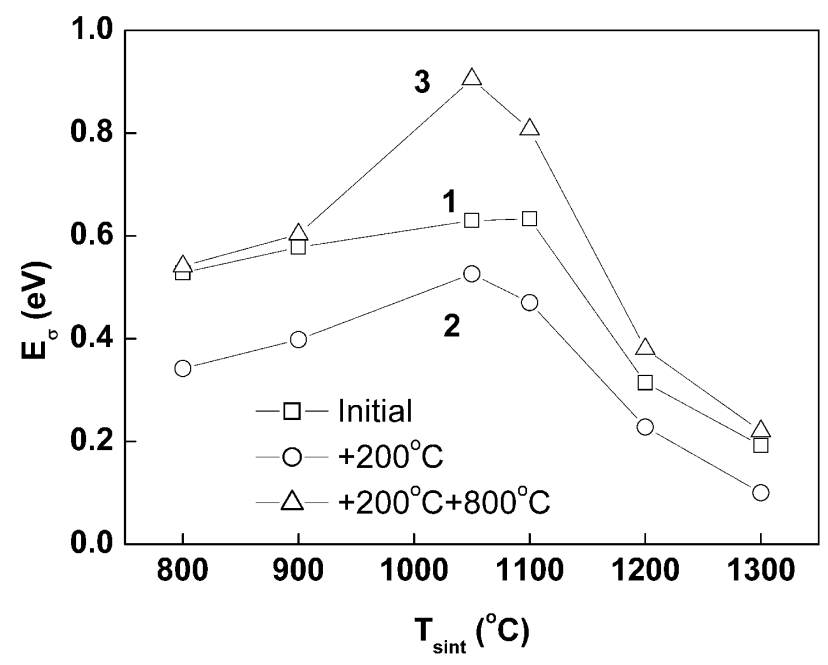

Fig.6. Activation energy of electrical conduction versus $\mathrm{T}_{\text {SINT }}$ measured after the additional heat treatment in air (1) at $800{ }^{\circ} \mathrm{C}$ (during formation of electrodes) then (2) at $200{ }^{\circ} \mathrm{C}$ and then (3) at $800{ }^{\circ} \mathrm{C}$ again

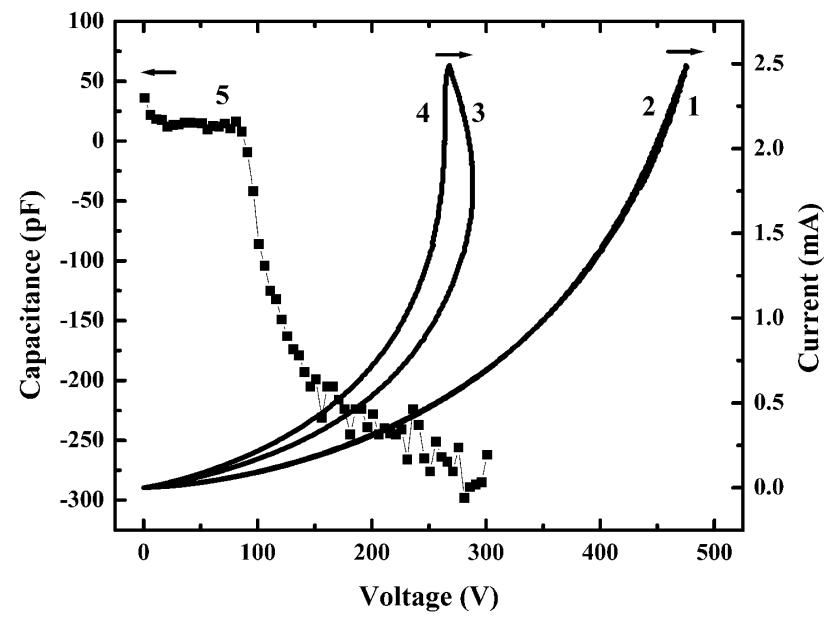

Fig. 7. Current (1-4) and capacitance (5) versus dc voltage for $\operatorname{In}_{2} \mathrm{O}_{3}-\mathrm{Bi}_{2} \mathrm{O}_{3}-\mathrm{Co}_{3} \mathrm{O}_{4}-\mathrm{Cr}_{2} \mathrm{O}_{3}$ ceramics. An overheating of a sample is absent ( 1 - at voltage increase, 2 - at voltage decrease). An overheating of a sample takes place (3 - at voltage increase, 4 - at voltage decrease). 